\title{
Softening Mechanisms of the AISI 410 Martensitic Stainless Steel Under Hot Torsion Simulation
}

\author{
Thiago Santana de Oliveira ${ }^{a}$, Eden Santos Silva ${ }^{a, b}$, Samuel Filgueiras Rodrigues ${ }^{a}$, Carmem Célia \\ Francisco Nascimento ${ }^{a}$, Valdemar Silva Leal ${ }^{a}$, Gedeon Silva Reis ${ }^{a}$ \\ ${ }^{a}$ PPGEM, Instituto Federal do Maranhão, Av. Getúlio Vargas, 04, Monte Castelo, 65030-005, São Luís, \\ MA, Brazil \\ ${ }^{b}$ Universidade Ceuma, Rua Josué Montello, Renascença, 1, 65075-120, São Luís, MA, Brazil
}

Received: October 24, 2016; Accepted: December 27, 2016

\begin{abstract}
This study investigated the softening mechanisms of the AISI 410 martensitic stainless steel during torsion simulation under isothermal continuous in the temperature range of 900 to $1150{ }^{\circ} \mathrm{C}$ and strain rates of 0.1 to $5.0 \mathrm{~s}^{-1}$. In the first part of the curves, before the peak, the results show that the critical $\left(\varepsilon_{c}\right)$ and peak $\left(\varepsilon_{\mathrm{p}}\right)$ strains are elevated for higher strain rate and lower temperatures contributing for higher strain hardening rate $(h)$. Moreover, this indicated that dynamic recrystallization (DRX) and dynamic recovery (DRV) are not effective in this region. After the peak, the reductions in stresses are associated to the different DRX/DRV competitions. For lower temperatures and higher strain rates there is a delay in the DRX while the DRV is acting predominantly (with low Avrami exponent $(n)$ and high $t_{0.5}$ ). The steady state was reached after large strains showing DRX grains, formation of retained austenite and the presence of chromium carbide $\left(\mathrm{Cr}_{23} \mathrm{C}_{6}\right)$ and ferrite $\delta$ at the martensitic grain boundaries. These contribute for impairing the toughness and ductility on the material. The constitutive equations at the peak strain indicated changes in the deformation mechanism, with variable strain rate sensitivity $(\mathrm{m})$, which affected the final microstructure.
\end{abstract}

Keywords: Martensitic steel AISI 420, dynamic recrystallization, dynamic recovery, stackingfault energy.

\section{Introduction}

During hot forming processes, stainless steels are subjected to variations in temperature and strain rate, generating changes in the mechanical and microstructural behavior of the alloy ${ }^{1-3}$. The main hot working processes are forging and rolling, followed by heat treatment, in which the material is subjected to thermal cycles under variable strains in order to improve their mechanical properties ${ }^{3}$. In this thermomechanical cycle, materials initially undergo a hardening process, followed by slow dynamic recovery and predominantly dynamic recrystallization, which are dictated by the stacking-fault energy (SFE) and the applied stain conditions ${ }^{4}$.

Stainless steels tend to soften by dynamic recrystallization (DRX), after a certain amount of deformation ${ }^{1,5-6}$. This threshold deformation, which is known as the critical strain $\left(\varepsilon_{c}\right)$, corresponds to the minimum deformation necessary for the onset of DRX, and the stress corresponding to this strain is called critical stress $\left(\sigma_{c}\right)^{7-10}$. This value corresponds to the upper limit of the amount of energy that can be stored locally in this type of hot deformed material. However, the critical amount of stored energy alone is not enough to trigger the onset of DRX, which also requires the energy dissipation rate to reach a critical value. Poliak and Jonas, who applied

* e-mail: samuel.filgueiras@ifma.edu.br the principle of thermodynamic irreversibility, determined that the critical state for the onset of DRX occurs when ${ }^{11,12}$ :

$$
\frac{\partial}{\partial \sigma}\left(-\frac{\partial \theta}{\partial \sigma}\right)=0
$$

where $\theta$ is the work hardening rate. The values of $\theta$ can be obtained by calculating the derivative of the $\sigma$ vs. $\varepsilon$ curve measured experimentally, Eq. $2^{12}$ :

$$
\theta=\frac{\partial \sigma}{\partial \varepsilon}
$$

The $\theta$ vs. $\varepsilon$ curves are then plotted to evaluate the width (w) and depth (d) of the dip generated in the dynamic recovery of the material, using the parameters of $t_{0.5}$ and Avrami exponent (n), considering the conditions of temperature and strain rate.

In the downward slope of the curve after the peak deformation, the fraction of dynamic recovery $\left(\mathrm{X}_{\mathrm{s}}\right)$ is determined as a function of applied strain $(\varepsilon)$, and the parameter $t_{0.5}$ (time to reach $50 \%$ of softening) is estimated from this curve:

$$
X_{S}=\frac{\left[\sigma_{P}-\sigma_{i}\right]}{\sigma_{P}-\sigma_{S S}}=1-\exp \left[-0.693\left(\frac{t}{t_{0.5}}\right)^{n}\right]
$$

where $\sigma_{\mathrm{p}}$ is the peak stress and $\sigma_{\mathrm{ss}}$ is the steady-state stress with complete DRX. Still based on this model, the 
Avrami exponent (n) was determined by means of the $\log$ $[\ln (1 /(1-X))]$ vs. $\log t$ graph, where $\mathrm{n}$ equals the angular coefficient of a straight line ${ }^{13}$.

The AISI 410 martensitic stainless steel with $11.77 \%$ chromium and $0.12 \%$ carbon content has emerged as a lowcost alternative for applications that combine good mechanical strength and corrosion resistance ${ }^{14}$. This steel can be used in the oil and natural gas extraction industry, turbine blades, compressors, rods, valves, shafts and bearings. AISI 410 steel has a body-centered tetragonal (BCT) crystal structure with low $\mathrm{C}$ content and high hardenability, owing mainly to the presence of nickel, cobalt and copper, which stabilize austenite and enable martensitic transformation. A balanced addition of chromium is essential for the formation of martensite after tempering, since it arises from the transformation of austenite ${ }^{15}$. This steel has low SFE due to the presence of austenite, and DRX is essential to prevent the formation of defects prior to martensitic transformation, whereby the austenite grains are refined through metallurgical processes. However, because this martensitic stainless steel has only been developed recently, many of its properties are still being investigated, which justifies its study and characterization under hot deformation on a laboratory scale. Thus, the aim of this study is to characterize the hot deformation of AISI 410 martensitic stainless steel based on isothermal continuous hot torsion tests, through constitutive analysis and parameterization of the phenomena that occur during dynamic recovery.

\section{Materials and methods}

The steel was supplied in the form of $6.0 \mathrm{~m}$ long by $3 / 4$ inch diameter cylindrical bars. The chemical composition of the steel is described in Table 1.

The bars were machined into torsion samples with one end threaded to adjust and fix them onto the torsion machine. The specimens were subjected to the isothermal continuous hot torsion tests. The heating rate applied was of $2.0^{\circ} \mathrm{C} / \mathrm{s}$ up to the temperature of $1100^{\circ} \mathrm{C}$, where the samples were held for $300 \mathrm{~s}$ to homogenize the microstructure. After, they were then cooled at the same rate, to the test temperatures of $950^{\circ} \mathrm{C}, 1000^{\circ} \mathrm{C}, 1050^{\circ} \mathrm{C}$ and $1100^{\circ} \mathrm{C}$, and held there for 30 $\mathrm{s}$ to eliminate thermal gradients before being deformed at strain rates of $0.1 \mathrm{~s}^{-1}, 0.5 \mathrm{~s}^{-1}, 1.0 \mathrm{~s}^{-1}$ and $5.0 \mathrm{~s}^{-1}$, until the strain reached 3.5 or they ruptured.

The test parameters were programmed and controlled by a microcomputer with an interface program linked to the machine and designed specifically for this type of experiment. The responses were presented in the form of an equivalent stress $(\sigma)$ vs. strain $(\varepsilon)$ graph. The equivalent stress and strain $\left(\sigma_{\text {eq }} ; \varepsilon_{\text {eq }}\right)$ was calculated using the Von Mises relations, based on the Fields and Backofen method ${ }^{16}$, where the curves are dependent on the torque (M) and the rotation angle $(\theta)$, Equations 4 and 5:

$$
\begin{gathered}
\sigma_{e q}=\frac{\sqrt{3 M}}{2 \pi R^{3}}(3+m+n) \\
\varepsilon_{e q}=\left[\frac{R}{\sqrt{3 L}}\right] \theta
\end{gathered}
$$

where $\mathrm{R}$ is the radius and $\mathrm{L}$ is the length of the useful portion of the test specimen. The coefficients $n$ and $m$ represent the work hardening and strain rates, respectively.

After the usual metallographic procedure, the microstructure was analyzed under a Nikon Eclipse optical microscope. Before examining the microstructure, the material was chemically etched using Vilella's reagent. Details of the competing DRV and DRX phenomena were confirmed by scanning electron microscopy (SEM), in which the microanalysis to identify the phases in the material were also made by EDS.

After plotting the curves, the characteristic points were determined using the well-known methodology proposed by Poliak \& Jonas ${ }^{17}$. The values of critical stress and strain $\left(\sigma_{c}\right.$, $\left.\varepsilon_{c}\right)$ were determined starting from the minimum point of the $(-\mathrm{d} \theta / \mathrm{d} \sigma$ vs. $\sigma)$ curve, where dynamic recrystallization begins at the inflection point of the $\theta$ vs. $\sigma$ curve. The values of peak stress $\left(\sigma_{\mathrm{p}}, \varepsilon_{\mathrm{p}}\right)$, steady-state stress $\left(\sigma_{\mathrm{ss}}, \varepsilon_{\mathrm{ss}}\right)$ and saturation stress $\left(\sigma_{\text {sat }}, \varepsilon_{\text {sat }}\right)$ were determined analytically from the $\theta$ vs. $\sigma$ and $\theta$ vs. $\varepsilon$ curves, at the points where the work hardening rate $(\theta=0)$ is zero.

\section{Results and Discussion}

\subsection{Flow stress curves}

The flow stress curves under isothermal continuous hot torsion testing of the steel at a constant temperature and variable strain rates are illustrated in Figure 1. The stresses increase until reach a limit. This region presents a high level of work hardening, particularly in conditions of low temperature and high strain rate, where the plastic flow curves become steeper. At this stage as the thermal activation mechanisms and dislocation mobility are limited, the work hardening is predominant which prevents the action of dynamic recovery. This shifted the critical strain $\left(\varepsilon_{\mathrm{c}}\right)$ to higher values and consequently the onset of dynamic recrystallization occurs from this point where the curve neatly changes its slope. On the other hand, note that, as the temperature increases and the strain rate decreases, the curves becomes smoother,

Table 1. Chemical composition of AISI 410 martensitic stainless steel (mass\%)

\begin{tabular}{lcccccccccc}
\hline Material & $\% \mathrm{C}$ & $\% \mathrm{Si}$ & $\% \mathrm{Mn}$ & $\% \mathrm{P}$ & $\% \mathrm{~S}$ & $\% \mathrm{Cr}$ & $\% \mathrm{Ni}$ & $\% \mathrm{Mo}$ & $\% \mathrm{Fe}$ \\
\hline AISI 410 & 0.120 & 0.440 & 0.250 & 0.027 & 0.001 & 11.770 & 0.260 & 0.070 & bal \\
\hline
\end{tabular}






(a)

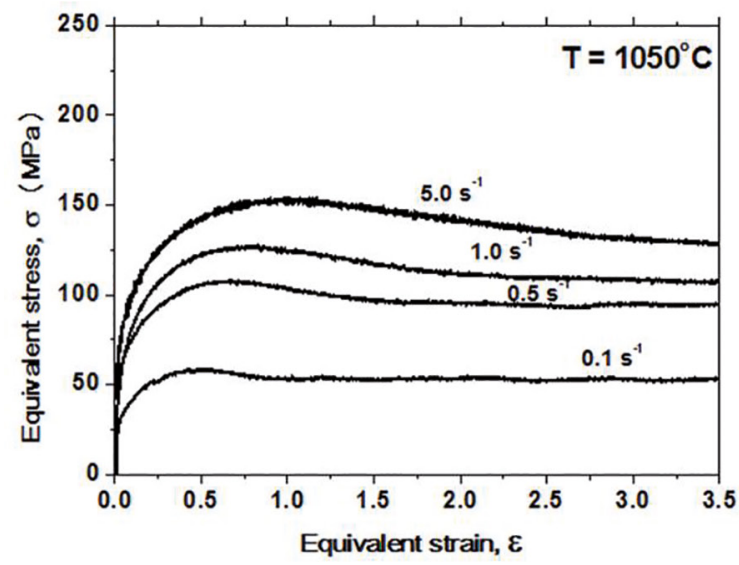

(c)

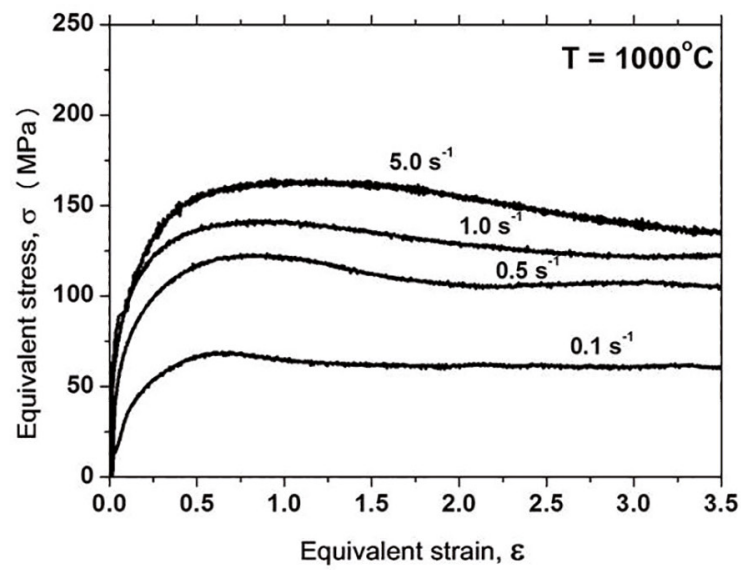

(b)

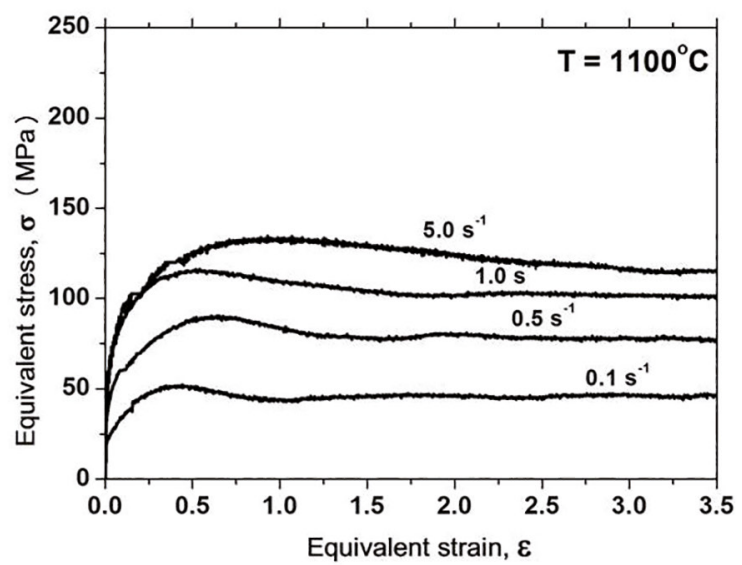

(d)

Figure 1. Stress-strain diagram of AISI 410 martensitic stainless steel at constant temperature and variable strain rates: (a) $950^{\circ} \mathrm{C}$, (b) $1000^{\circ} \mathrm{C}$, (c) $1050^{\circ} \mathrm{C}$, (d) $1100^{\circ} \mathrm{C}$.

indicating the dynamic recovery (DRV) of the material until it reaches its peak stress, at which point the mechanisms of work hardening and dynamic softening is balanced locally.

After the peak strain, the stresses drop to an intermediate value $\left(\sigma_{\mathrm{ss}}\right)$ which is governed by the temperature and strain rate. These accelerate the kinetics of dynamic softening leading to a steady state stress, where the hardening and softening mechanisms establish a dynamic balance at further strains. However, in the condition at low temperatures and higher strain rates, i.e. $5.0 \mathrm{~s}^{-1}$, it seems that the curves show a sluggish decrease in the stress level resulting from the dominant role of dynamic recovery mechanism. This contributed to generating a delay in the action of the thermally activated mechanisms and consequently the dynamic recrystallization.

\subsection{Characteristic points of the curves}

The characteristic points on the curves were determined using the methodology already described in section 2 . The dependence of peak strain and steady strain on temperature and strain rate is shown in Figure 2(a) and (b) respectively. Note the tendency of the strain to decline in response to increasing temperature and decreasing strain rate favoring the dynamic recrystallization. However, there are some variations in behavior. There is a visible increase in the steadystate strain $\left(\varepsilon_{\mathrm{ss}}\right)$ in the condition of intermediate temperature $\left(1050^{\circ} \mathrm{C} / 0.5 \mathrm{~s}^{-1}\right)$, indicating that greater deformation is required to complete the process of dynamic recrystallization, which the dynamic recovery is more effectiveness. Note that the difference between the peak and steady-state strains $(\Delta \varepsilon=$ $\left.\varepsilon_{\mathrm{ss}}-\varepsilon_{\mathrm{p}}\right)$ decreases with increasing temperature and decreasing strain rate because dynamic recrystallization in these conditions is more intense. However, because the phenomenon of dynamic recovery occurs during the hot deformation of AISI 410 steel, there is a delay in the kinetics of dynamic recovery, which is expressed by the relation $\varepsilon_{\mathrm{p}} / \varepsilon_{\mathrm{ss}} \sim 0.32$.

The behavior of stress $(\sigma)$ as a function of the strain rate applied in two different regions of the flow stress curves: at close to the peak strain $\left(\varepsilon_{\mathrm{p}} \sim 0.5\right)$ and at the steady-state $\operatorname{strain}\left(\varepsilon_{\mathrm{ss}} \sim 3.5\right)$ is shown in Figure 3. As can be seen, there 


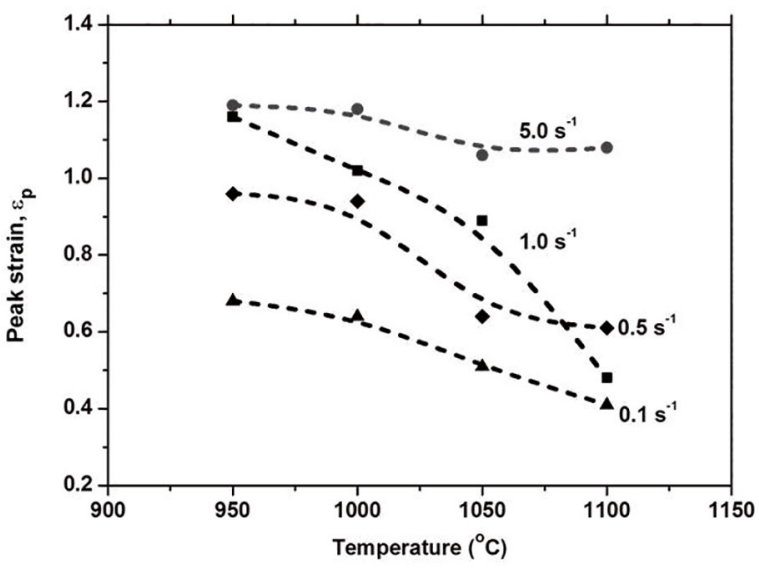

(a)

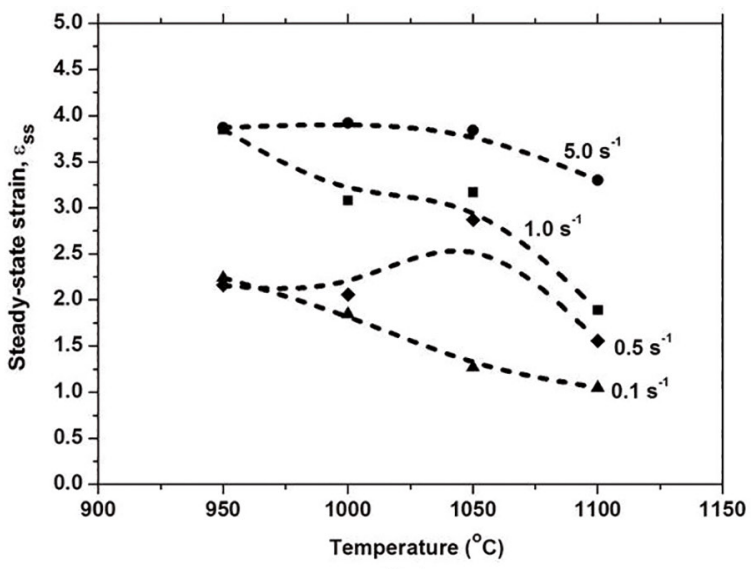

(b)

Figure 2. Dependence of (a) peak $\left(\varepsilon_{\mathrm{p}}\right)$ and (b) steady-state strains $\left(\varepsilon_{\mathrm{ss}}\right)$ on temperature and strain rate.

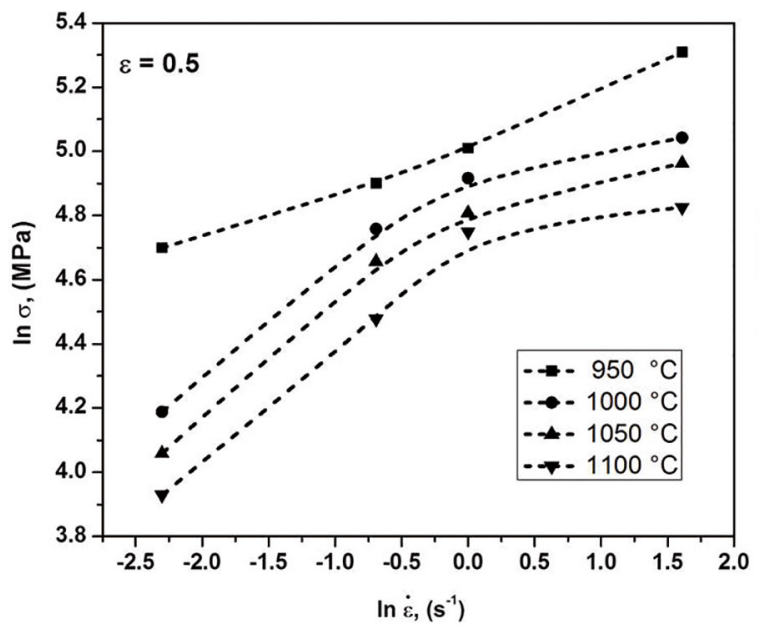

(a)

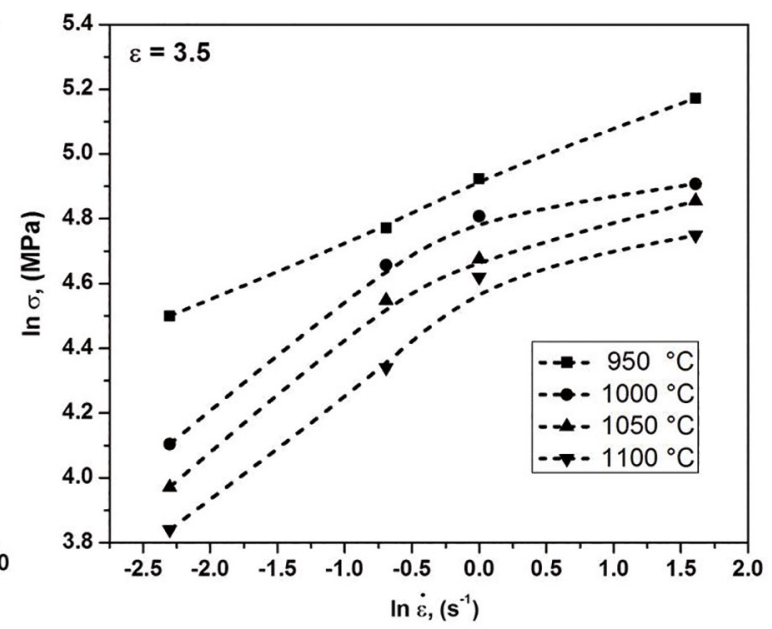

(b)

Figure 3. Determination of strain rate sensitivity (m) in the conditions of hot deformation. (a) 0.5 and (b) 3.5 strains.

are two different behaviors with different slopes, indicating a possible change in deformation mechanism.

\subsection{Evaluation of dynamic recovery}

The work hardening rate $(\theta)$ behavior as a function of applied strain $(\varepsilon)$, where the negative $\theta$ points correspond to the region of dynamic softening after the peak strain, is depicted in Figure 4. The profile of the curve enables one to evaluate the effect of the strain rate and temperature on the softening kinetics, where the lowest point in the dip represents the strain $(\varepsilon)$ at the highest rate of dynamic softening, which is higher the lower the strain rate. At a given strain rate, the width (w) of the curve decreases as the temperature increases (see Table 2). On the other hand, the width $(\mathrm{w})$ of the curve increases at a constant temperature and varying strain rate, indicating a delay the kinetics of dynamic recrystallization and evidence of dynamic recovery with more intense softening. However, in some conditions of low temperature and high strain rate, the point of steady-state strain is not reached.

\subsection{Constitutive equations}

The relationship between the flow curves, temperature and strain rate in the process of plastic deformation of the alloy can be expressed according to the relation ${ }^{18}$ :

$$
Z=\dot{\varepsilon} \exp \left(\frac{Q_{d e f}}{R T}\right)=A\left[\sinh \left(\alpha \sigma_{p}\right)\right]^{n}
$$

where $\dot{\varepsilon}$ is the strain rate, $\mathrm{Q}_{\text {def }}$ is the deformation activation energy $(\mathrm{kJ} / \mathrm{mol}), R$ is the universal gas constant $(8.31 \mathrm{~J} / \mathrm{mol} . \mathrm{K})$, $T$ is the absolute temperature $(\mathrm{K}), Z$ is the Zener-Hollomon parameter, and $\sigma_{\mathrm{p}}$ is the peak stress (MPa). The variables $A$, $\alpha$ and $n$ are constants that depend on the material ${ }^{19}$. After 


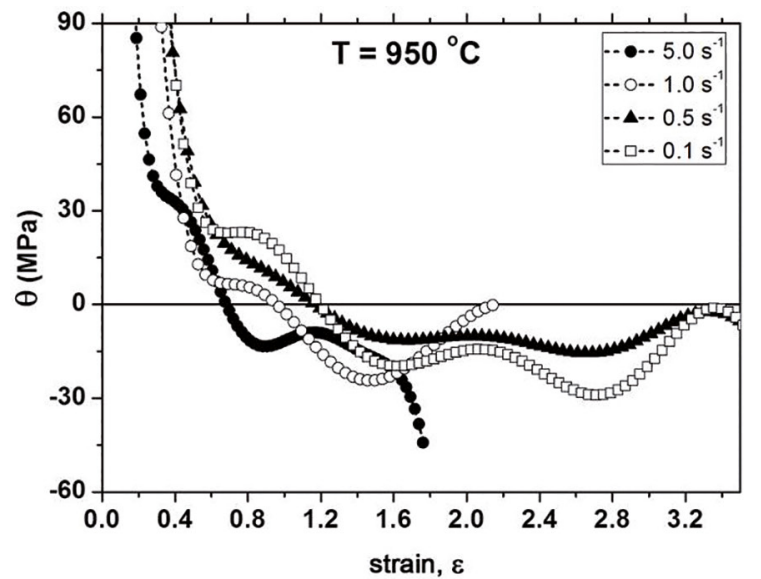

(a)

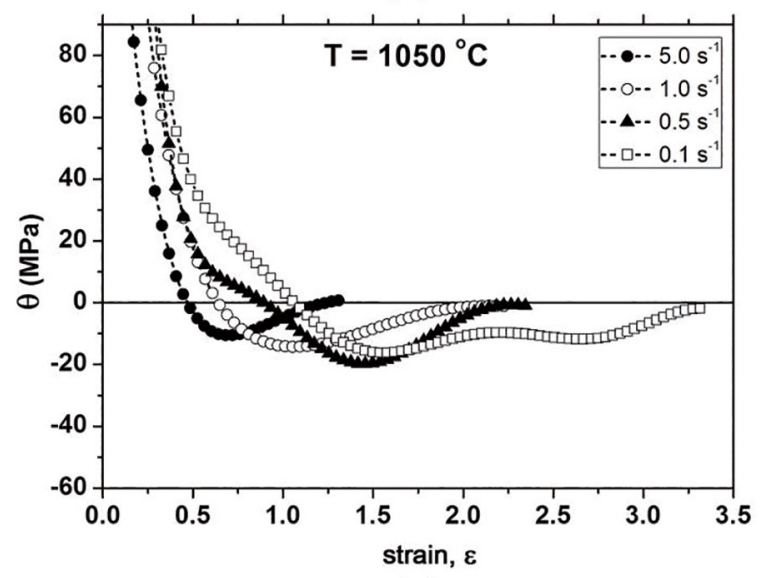

(c)

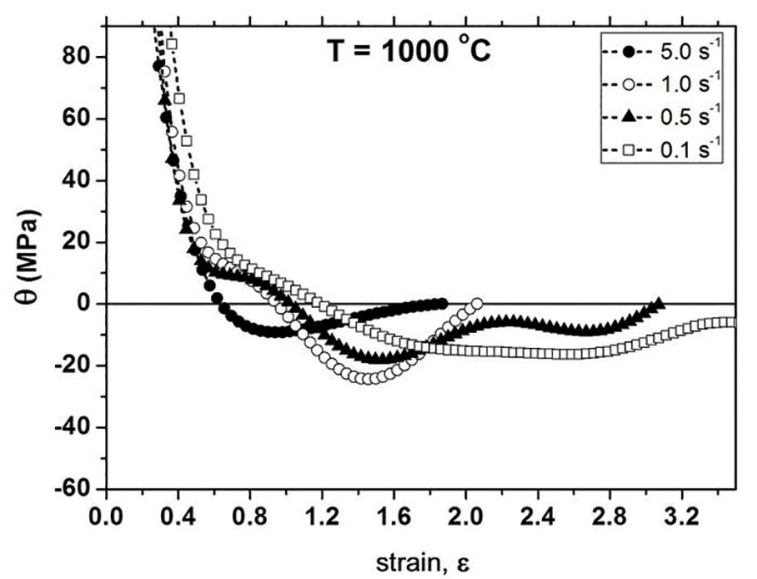

(b)

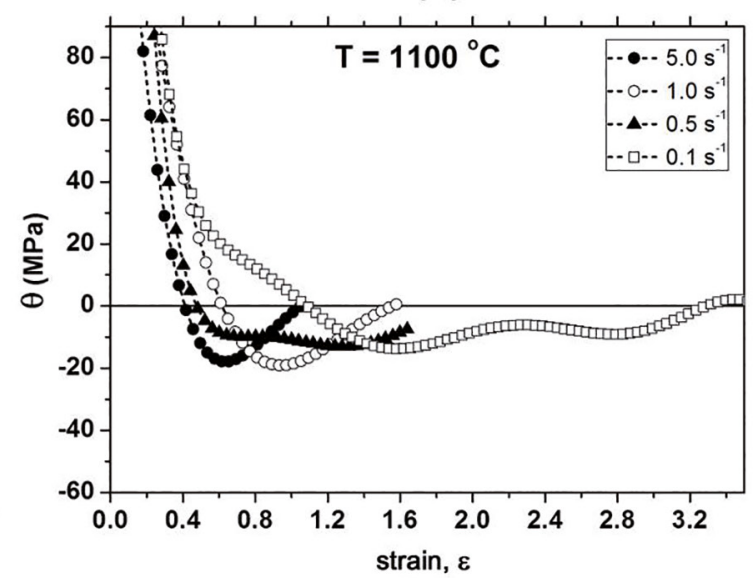

(d)

Figure 4. Behavior of the $\theta \times \varepsilon$ curve at temperatures of (a) $\mathrm{T}=950 \mathrm{oC},(\mathrm{b}) \mathrm{T}=1000^{\circ} \mathrm{C}$, (c) $\mathrm{T}=1050^{\circ} \mathrm{C}$ and (d) $\mathrm{T}=1100^{\circ} \mathrm{C}$, determination of the parameters $\mathrm{w}$ and $\mathrm{p}$.

Table 2. Values of the Avrami exponent (n), 50\% of softening time (t0.5), width (w) and depth (d) of the dip in dynamic recovery

\begin{tabular}{|c|c|c|c|c|c|}
\hline $\mathrm{T}\left({ }^{\circ} \mathrm{C}\right)$ & rate $\left(\mathrm{s}^{-1}\right)$ & $\mathrm{n}$ & $\mathrm{t}_{0,5}$ & $\mathrm{w}$ & $\mathrm{d}(\mathrm{MPa})$ \\
\hline \multirow{4}{*}{$0.1 \mathrm{~s}^{-1}$} & 950 & - & - & - & - \\
\hline & 1000 & 1.97 & 4.72 & & 16.4 \\
\hline & 1050 & 1.82 & 3.42 & 2.1 & 16.9 \\
\hline & 1100 & 1.91 & 3.12 & - & 14.5 \\
\hline \multirow{4}{*}{$0.5 \mathrm{~s}^{-1}$} & 950 & 1.43 & 0.98 & 2.1 & 15.4 \\
\hline & 1000 & 1.79 & 0.99 & 2.0 & 17.9 \\
\hline & 1050 & 1.77 & 1.16 & 1.4 & 21.3 \\
\hline & 1100 & 2.73 & 0.79 & - & 14.1 \\
\hline \multirow{4}{*}{$1.0 \mathrm{~s}^{-1}$} & 950 & 1.75 & 1.27 & 1.2 & 24.9 \\
\hline & 1000 & 1.18 & 0.85 & 1.1 & 24.7 \\
\hline & 1050 & 1.68 & 0.69 & 1.2 & 14.5 \\
\hline & 1100 & 1.94 & 0.72 & 0.98 & 19.7 \\
\hline \multirow{4}{*}{$5.0 \mathrm{~s}^{-1}$} & 950 & 1.86 & 0.25 & - & 13.9 \\
\hline & 1000 & 1.90 & 0.25 & 1.2 & 9.3 \\
\hline & 1050 & 1.37 & 0.22 & 0.8 & 10.7 \\
\hline & 1100 & 1.36 & 0.19 & 0.6 & 18.5 \\
\hline
\end{tabular}


some manipulations, one arrives at two relations that enable one to determine the stress exponent (n) and the activation energy $\left(\mathrm{Q}_{\text {def }}\right)$ :

$$
\begin{gathered}
n=\left.\frac{\partial \ln \dot{\varepsilon}}{\partial \ln \left[\sin \left(\alpha \sigma_{p}\right)\right]}\right|_{T} \\
Q_{\text {def }}=\left.\frac{n R \partial \ln \left[\sinh \left(\alpha \sigma_{p}\right)\right]}{\partial(1 / T)}\right|_{\dot{\varepsilon}}
\end{gathered}
$$

The least squares method was used to determine the value of $\alpha=0.00924 \mathrm{MPa}^{-1}$, which presented the lowest standard deviation. Then, the $\ln \varepsilon$ vs. $\ln \left[\sinh \left(\alpha \sigma_{\mathrm{p}}\right)\right]$ curves were plotted to estimate the average value of the exponent $\mathrm{n}=3.18$, from the slopes of the straight lines (Figure 5(a)). After obtaining the values of $\alpha$ and $n$, the $\ln \left[\sinh \left(\alpha \sigma_{\mathrm{p}}\right)\right]$ vs. $1 / \mathrm{T}$ curves were plotted (Figure 5(b)), where the slopes enabled the calculation of the activation energy, $\mathrm{Q}_{\text {def }}=205$ $\mathrm{kJ} / \mathrm{mol}$, which is necessary to overcome the barriers in the hot forming process. The value of the constant $\mathrm{A}=5.54 \mathrm{x}$ $107 \mathrm{~s}^{-1}$ was determined by linear regression of $\ln \left[\sinh \left(\alpha \sigma_{\mathrm{p}}\right]\right.$ vs. $\ln Z$, with a correlation coefficient of 0.97 (Figure 5(c)). After determining the values of $\mathrm{Q}, \alpha, n$ and $A$, a constitutive equation is proposed for the peak stress $\left(\sigma_{\mathrm{p}}\right)$ as a function of $\mathrm{Z}$ :

$$
\sigma_{p}=108.22\left[\sinh ^{-1}\left(1.8 \times 10^{-8} z\right)^{0.31}\right]
$$

This constitutive equation for $\sigma_{p}$ as a function of the deformation conditions and the intrinsic characteristics of the material can be used to predict the levels of strength of AISI 410 martensitic stainless steel over a wide range of workability in hot rolling processing, forging, etc.

\subsection{Analysis of the $\sigma$ vs. \& curve, before the peak}

The first part of the flow stress curves, shown in Figure 1, indicted high levels of strain hardening coefficient $(\boldsymbol{h})$ at low temperatures and high strain rates, determined according to methodology shown in Reference 19, expressed in Figure 6. After a slight strain, one can see that the coefficient of DRV (r), which specifies the inflection of the plastic flow curve, which is determined from the slope of the $\theta . \sigma \mathrm{vs} . \sigma^{2}$ curve, is higher as the temperature increases and the strain rate decreases (Figure 6).

The strain hardening coefficient $(\boldsymbol{h})$ as a function of peak stress $\left(\sigma_{\mathrm{p}}\right)$ and parameter $Z$ of power law tends to increase with increasing strain rate and decreasing temperature, resulting in more effective hardening in the first part of the stress-strain curves. This high value of $\mathrm{h}$ is due to the low value of SFE $\sim \mathrm{mJ} / \mathrm{m}^{2}$ with delay of the action of thermally affected mechanisms, resulting in an increase in the work hardening rate. Using the method proposed by Dai et. al. ${ }^{4}$, not shown here, the calculated value of the SFE for this steel was approximately $21 \mathrm{~mJ} / \mathrm{m}^{2}$.
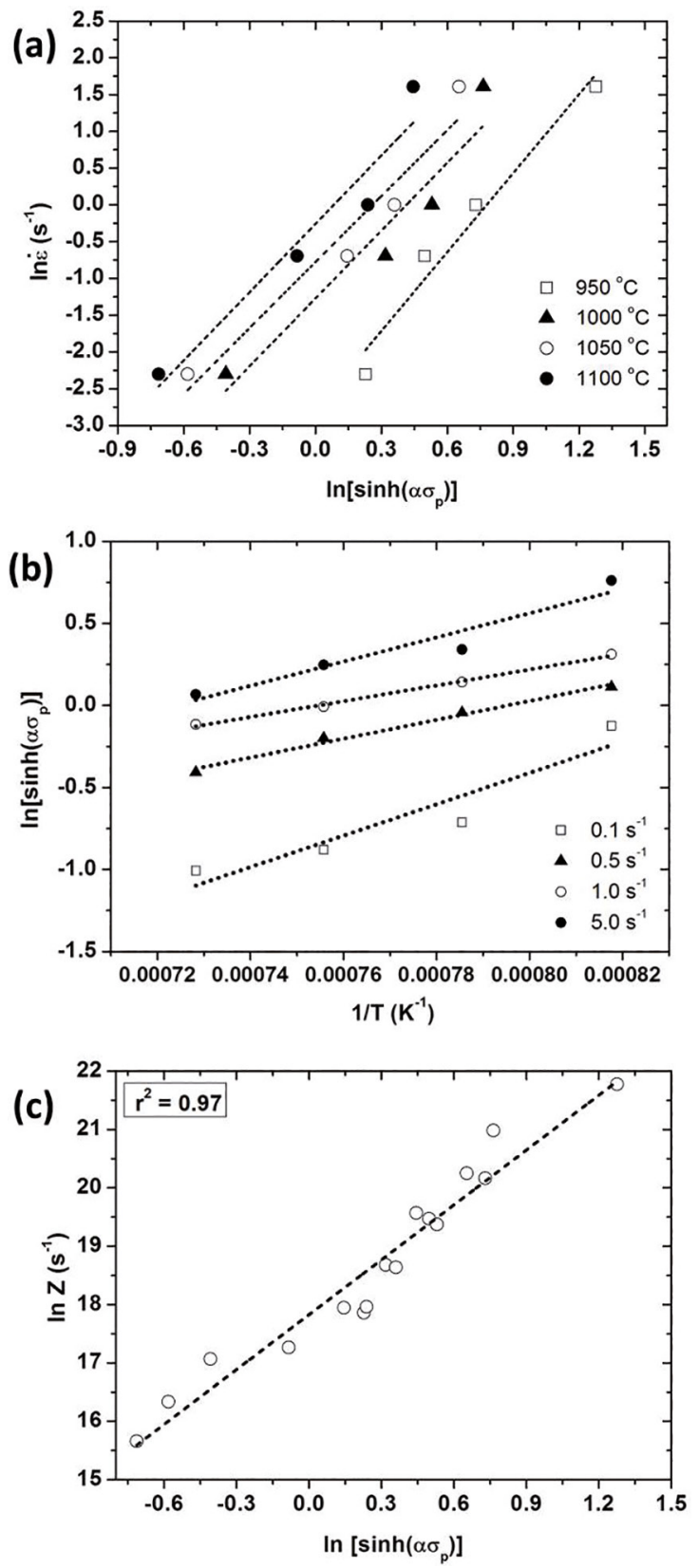

Figure 5. Plots for determination of the constants (a) n, (b) the activation energy for hot deformation (Qdef) and (c) A.

The coefficient $\mathrm{h}$ contributes to increase the level of stress during deformation on the upward slope of the curve, modifying its profile, particularly at low temperature and high strain rates (High Z). The literature reports that in this stage, there is formation and increased density of dislocations, which accumulate and interact, entrapping and forming sub-grains with reduced mobility, requiring a higher stress level to trigger greater plastic deformation ${ }^{20-22}$. However, the operations of thermally activated mechanisms, such as scaling and crossslip, favor the rearrangement and elimination of these defects, enabling the formation of substructures, reducing the work 


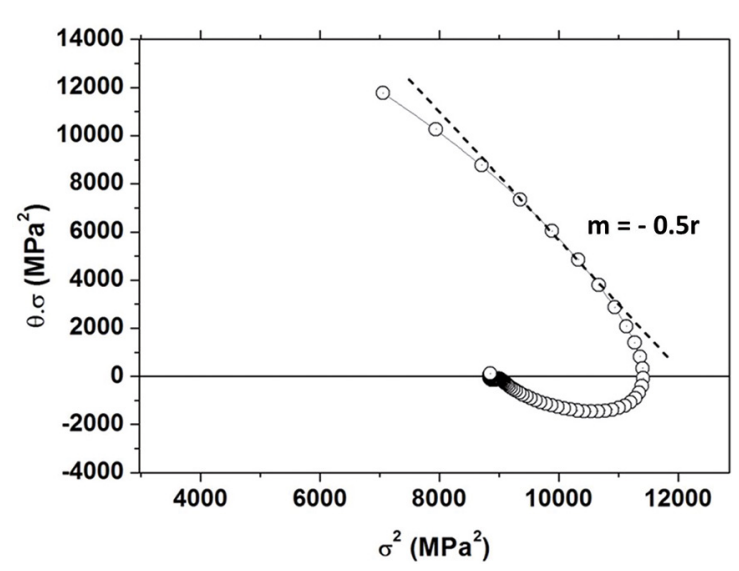

Figure 6. Determination of the coefficient of DRV (r) in hot deformation conditions, $\mathrm{m}=-0.5 \mathrm{r}$, condition of $1050^{\circ} \mathrm{C} / 5.0 \mathrm{~s}^{-1}$.

hardening rate parabolically and increasing the coefficient of dynamic recovery (r), as indicated in Figure 7.

In Figure 7, note that the behavior of the coefficient of DRV (r) decreases until it becomes constant in response to the peak stress $\left(\sigma_{\mathrm{p}}\right)$ and parameter $Z$ of power law. In other words, the $r$ value decreases in response to the increase in stress achieved at low temperature and high strain rate (higher $Z$ ). DRV is effective at higher temperatures, even with low SFE, and reaches the saturation point faster. On the other hand, the $\mathrm{h}$ and $\mathrm{r}$ coefficients present the opposite behavior in the test conditions because of the competing mechanisms of DRV and DRX, which occur concomitantly, with the low values of $Z$ and SFE providing a favorable condition for the occurrence of DRX, which reduced the levels of strain, particularly of $\varepsilon_{\mathrm{c}}$ and $\varepsilon_{\mathrm{p}}$, which characterize the onset of DRX. The constitutive equations found for the flow curve region before the peaks are shown as follow.

$$
\begin{gathered}
r=57.98 \times \sigma_{p}^{-0.47} \\
h=7.87 \times 10^{11} \sigma_{p}^{1.49} \\
r=66.01 \times z^{-0.13} \\
h=6.8 \times 10^{11} z^{0.27}
\end{gathered}
$$

\subsection{Analysis of the $\sigma$ vs. $\varepsilon$ curve, after the peak}

Figure 8 illustrates the behavior of the fraction of dynamic recovery $\left(\mathrm{X}_{\mathrm{S}}\right)$ as a function of deformation time, showing a sigmoidal profile that indicates the time spent to reach $50 \%$ of dynamic recovery, $t_{0.5}$. As can be seen, the recovery rate increases with temperature and strain rate. At the same temperature, $t_{0.5}$ decreases with increasing strain rate, since the process of deformation occurs more rapidly. At the same strain rate, $t_{0.5}$ decreases with increasing temperature, because of the more favorable condition for dynamic recrystallization resulting from the greater mobility of dynamically recrystallized grain boundaries.
Figure 9 depicts the behavior of $\log [\ln (1 / 1-X))]$ vs. $\log t$ for determination of the Avrami exponent (n). Note that the values of $\mathrm{n}$ range from 1.2 to 2.7 , and that these values fall within the range reported in the literature (Table 2 ). The highest $n$ values occur more frequently at higher temperatures and low strain rates, a condition in which the kinetics of dynamic recrystallization is accelerated. Note that some points do not show this tendency, probably because of a decline in grain nucleation and growth rates. Low $n$ values indicate retardation of the process of dynamic recovery.

\subsection{Influence of microstructure on the thermomechanical behavior}

The X-ray diffraction analysis in Figure 10 reveals the presence of martensitic phase (BCT structure) in samples solubilized at $1100{ }^{\circ} \mathrm{C}$ for $300 \mathrm{~s}$. This resulted from the diffusionless transformation of austenite during heat treatment, with $\mathrm{C}$ retained in the octahedral sites of martensite. This generates the $\mathrm{BCT}$ microstructure, which prevents movement at the grain boundaries, making the material harder. The fraction of martensite is dependent on cooling below the transition temperature.

The calculations of the phase diagram using FactSage 7.0 software indicated the formation of ferrite $\delta$ and austenite $\gamma$ phases and $\mathrm{M}_{23} \mathrm{C}_{6}$ carbides (see Figure 11). Studies in the literature ${ }^{1,5,14,23-26}$ report the formation of delta ferrite phase $(\delta)$ and chromium carbides at the martensitic grain boundaries in hot forming processes, possibly associated with sensitization or intergranular corrosion, even though martensite is not an equilibrium phase formed at high cooling rates, particularly due to the chemical composition of thermally activated $\mathrm{C}$ and $\mathrm{Cr}$ (Figure 11). These results are in agreement with the EDS microanalysis, which indicated the homogeneity of the chemical composition of the as received material. This phase strongly influences the microstructural transformations that occur in hot rolling processes, and can induce cracking and reduced toughness and ductility at high temperatures and low strain rates, which favors breakdown of the material, as can be seen in the curve at $950^{\circ} \mathrm{C}$ at $0.1 \mathrm{~s}^{-1}$.

Figures 12 show the microstructural transformations that occurred during the thermomechanical process. Coarse martensitic transformations are visible before the peak strain, Figure 12(a), with deformation twins resulting from the applied stresses in the shape of uniformly distributed needles (laths) possibly having the same crystallographic orientation. The microstructures also suggest the possibility of decarburization in the austenitic Widmanstätten structure in the form of laminae to better accommodate the stressinduced strain associated with the formation of martensite. Note the presence of $\delta$ ferrite grains (white regions) among the martensite grains, resulting from the instability of the system, which tends towards a final state of lower energy, i.e., greater stability, Figure 12 (a), (b), (c) and (d). 


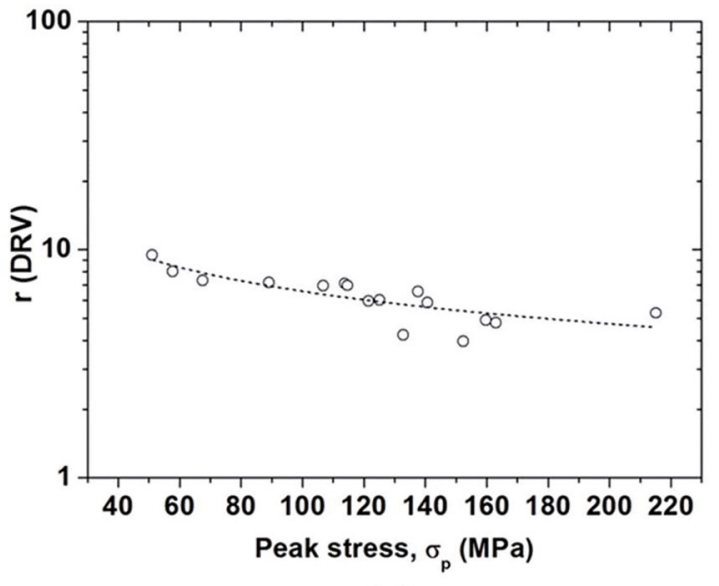

(a)

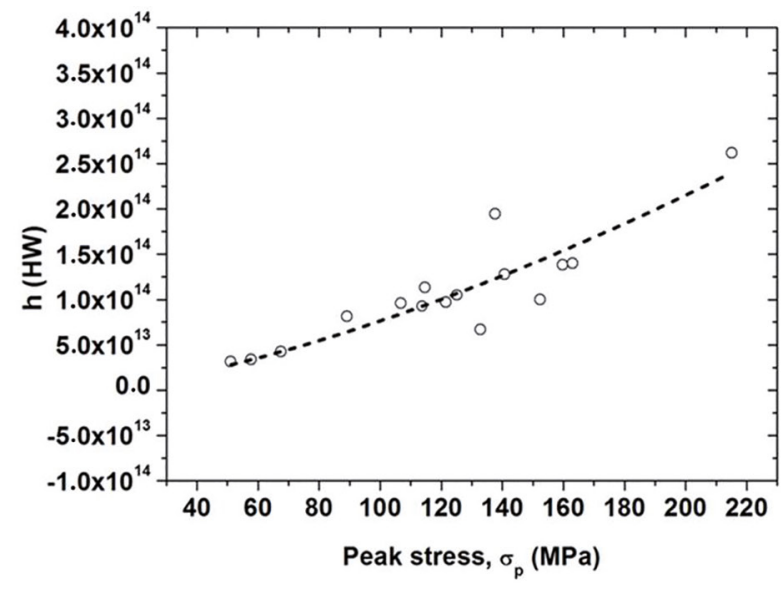

(b)

Figure 7. Dependence of coefficients (a) $r$ and $(b) h$ on peak stress $\left(\sigma_{p}\right)$.

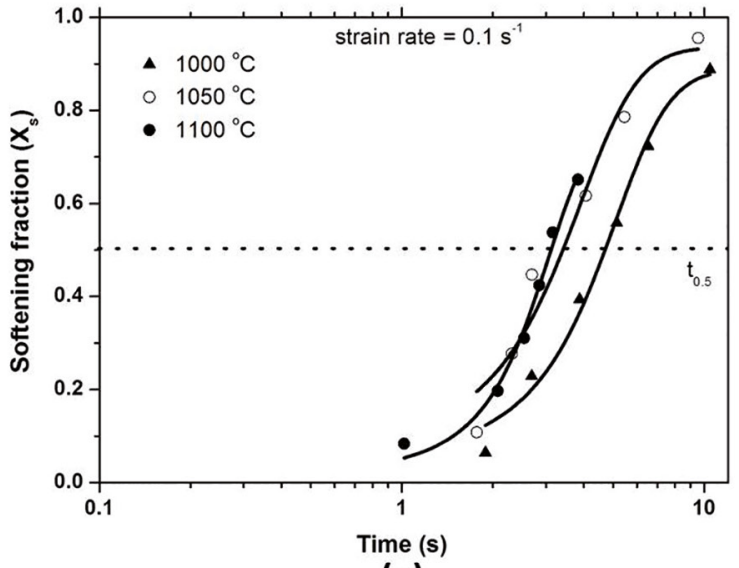

(a)

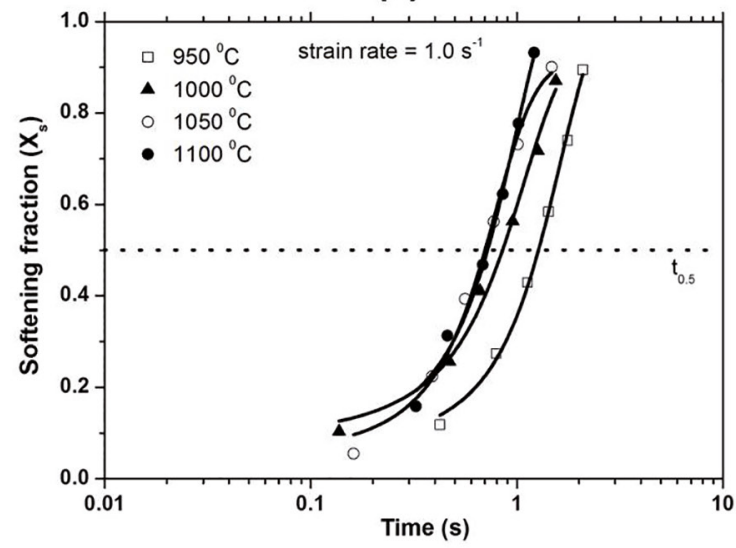

(c)

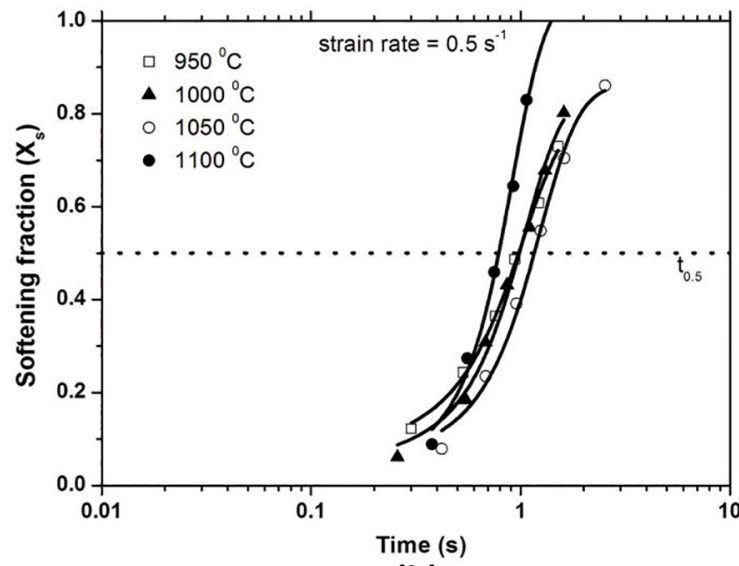

(b)

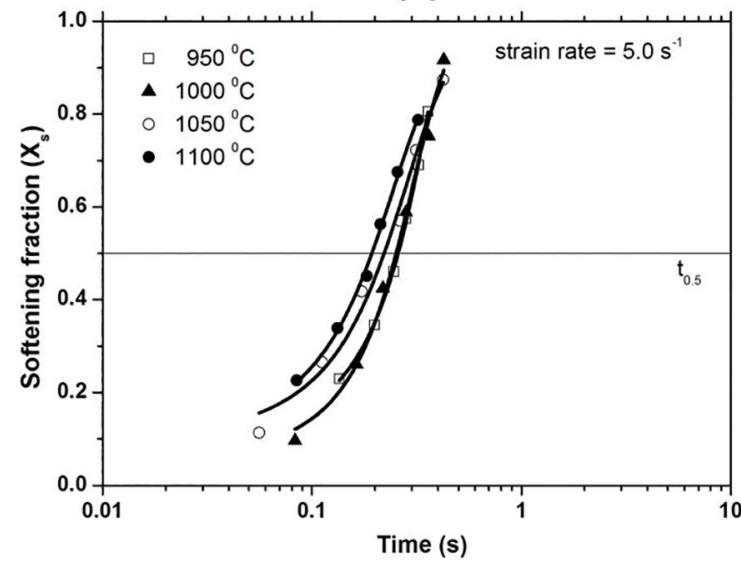

(d)

Figure 8. Diagram of the evolution of $X_{s}$ as a function of deformation time (t) at different strain rates: (a) $0.1 \mathrm{~s}^{-1}$, (b) $0.5 \mathrm{~s}^{-1}$, (c) $1.0 \mathrm{~s}^{-1}$ and (d) $5.0 \mathrm{~s}^{-1}$.

After the peak strain, Figure 12 (c), the microstructure shows a martensitic matrix with the presence of retained austenite between the needles resulting from incomplete martensitic transformation. Also, there are a considerable amount of $\delta$ ferrite at the grains, which are finer due to the higher levels of strain and the onset of thermally activated mechanisms. As can be seen, the presence of $\delta$ ferrite at the grains in a martensitic matrix could influence the material toughness because this phase dissolves almost no $\mathrm{C}$ in its matrix, Figure 12 (d). 


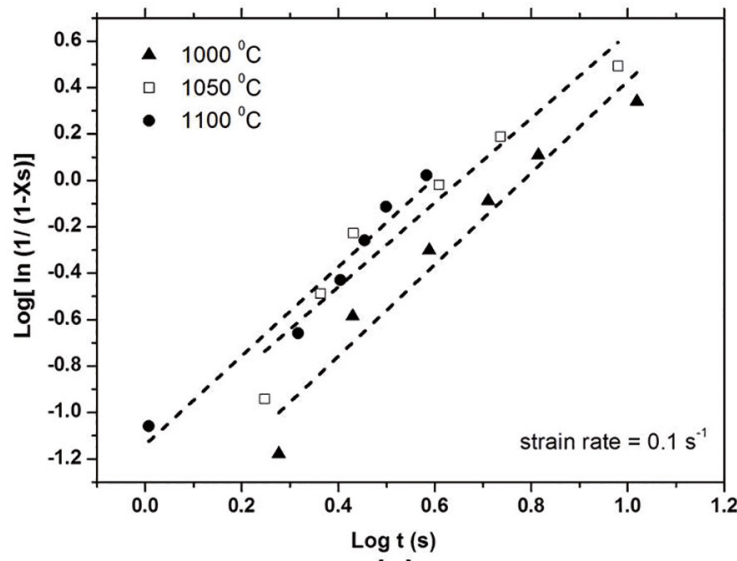

(a)

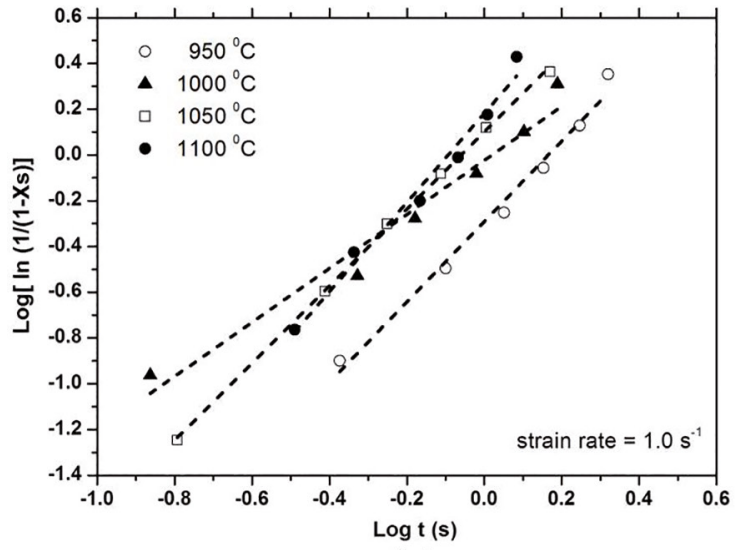

(c)

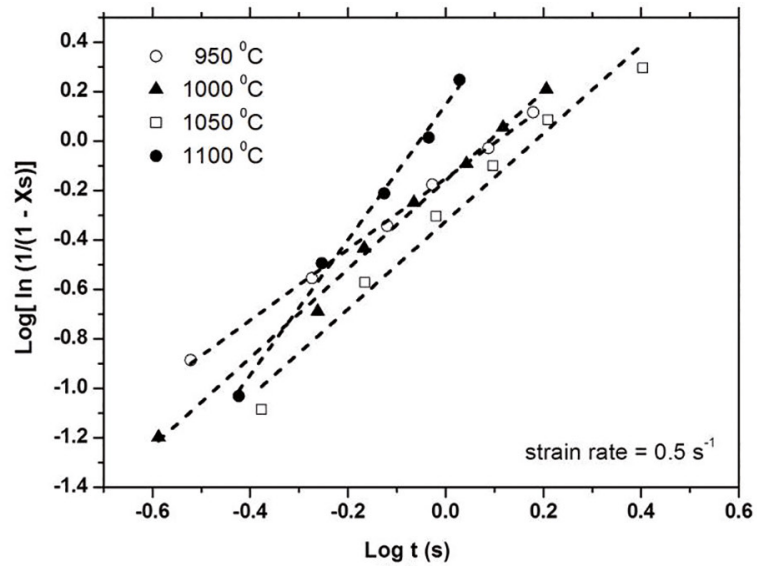

(b)

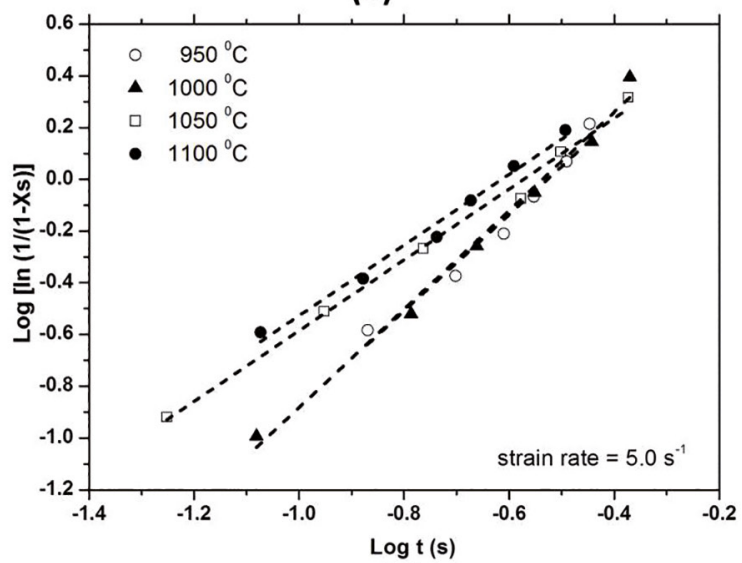

(d)

Figure 9. $\left.\log \left[\ln \left(1 / 1-X_{s}\right)\right)\right]$ vs. $\log t$ curves used to calculate the values of the Avrami exponent at different strain rates: (a) $0.1 \mathrm{~s}^{-1}$, (b) $0.5 \mathrm{~s}^{-1}$, (c) $1.0 \mathrm{~s}^{-1}$ and (d) $5.0 \mathrm{~s}^{-1}$.

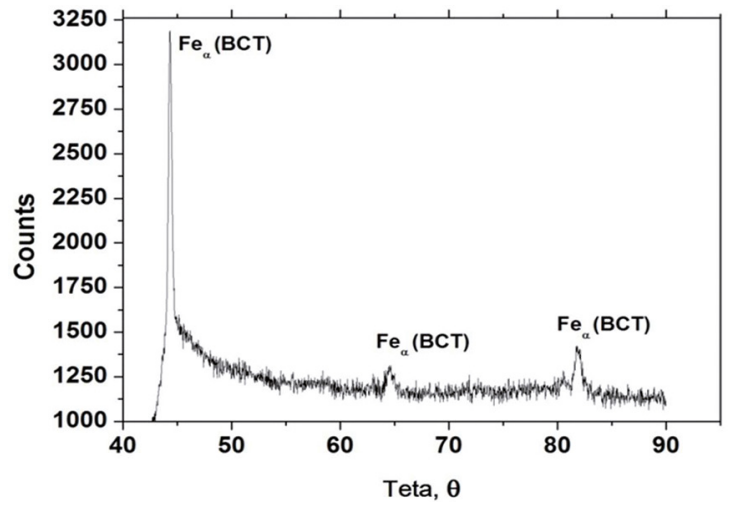

Figure 10. X-ray diffraction analysis of the as received samples of AISI 410 martensitic stainless steel (BCT structure).

Figure 13 shows the presence of $\mathrm{Cr}_{23} \mathrm{C}_{6}$ precipitates in the grain boundaries. These should reduce the steel toughness associated with the formation of $\delta$ ferrite which is more susceptible to phase transformations than austenite. Also the instability of $\delta$ ferrite may lead to the formation of secondary phases during heat treatments.

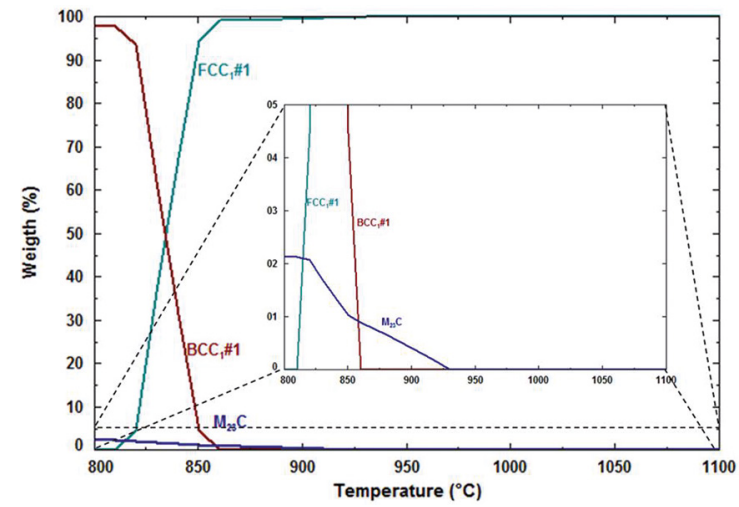

Figure 11. Phase diagram calculated by FactSage software 7.0 analysis of the AISI 410 martensitic stainless steel.

\section{Conclusions}

The focus of this study was the thermomechanical behavior of AISI 410 martensitic stainless steel in isothermal continuous hot torsion tests. The main results of these tests are summarized below. 


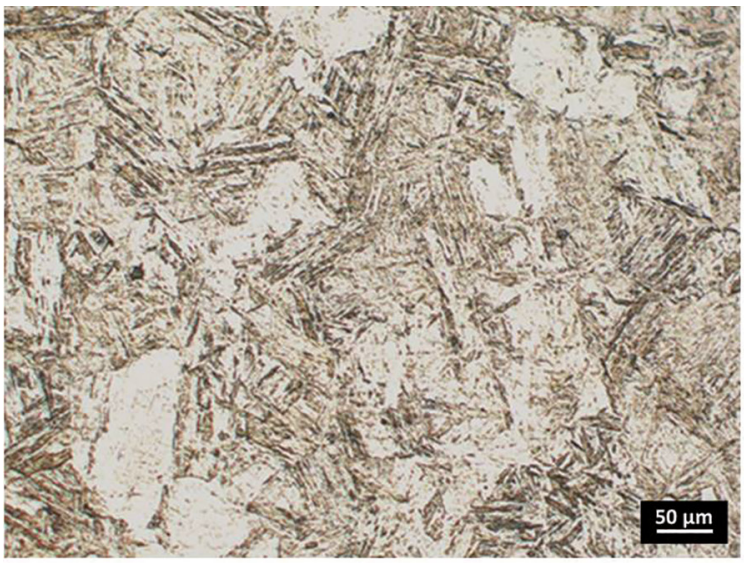

(a)

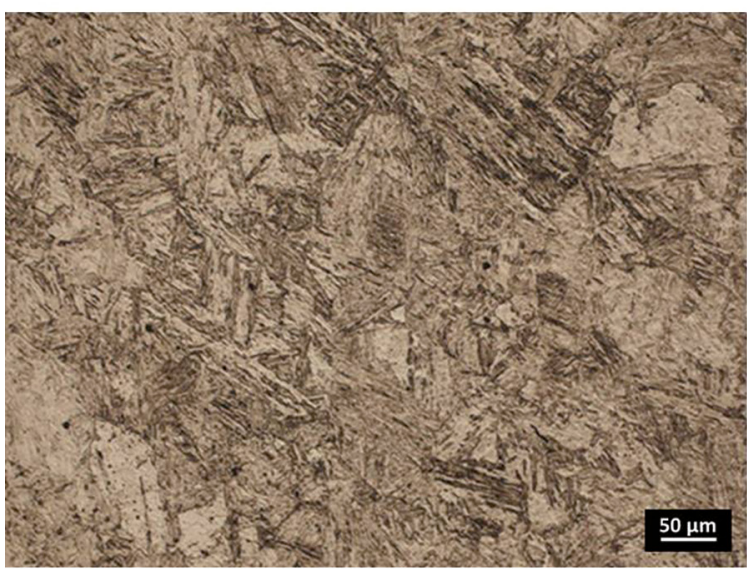

(c)

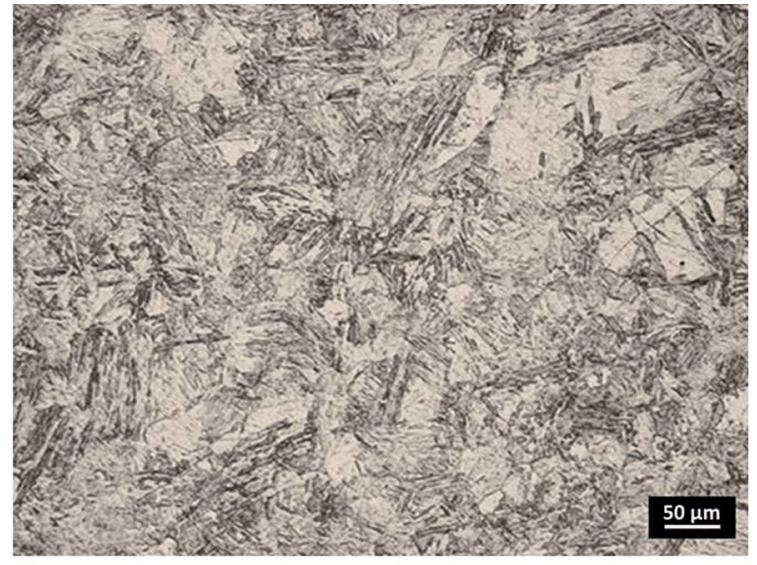

(b)

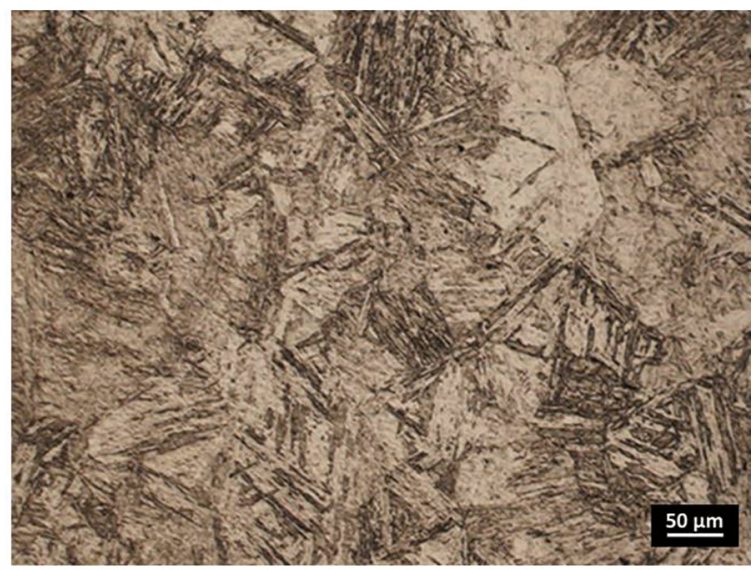

(d)

Figure 12. Optical microscopy of the steel along the plastic flow curves at $1050{ }^{\circ} \mathrm{C}$ : a) region before the peak, $\varepsilon=0.36,0.1 \mathrm{~s}^{-1} ; \mathrm{b}$ ) intermediate region, $\left.\varepsilon=2.42,5.0 \mathrm{~s}^{-1} ; \mathrm{c}\right) \varepsilon=2.03$ to $1.0 \mathrm{~s}^{-1}$ and d) Region before the peak, $\varepsilon=0.72$ to $5.0 \mathrm{~s}^{-1}$.

(a)

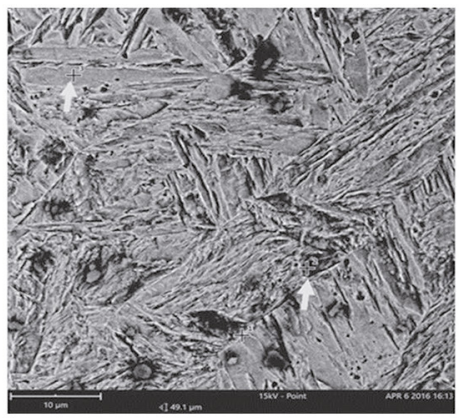

(b)

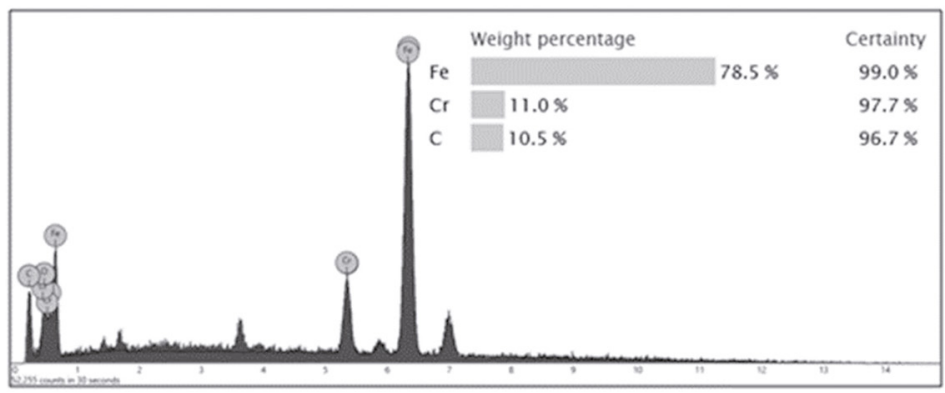

Figure 13. (a) SEM and (b) EDS analysis of in the conditions of $\mathrm{T}=1050^{\circ} \mathrm{C} ; \varepsilon=0.89$ and strain rate of $0.1 \mathrm{~s}^{-1}$. 
(i) On the first part of the curve, before the peak, the results indicated that the critical $\left(\varepsilon_{\mathrm{c}}\right)$ and peak $\left(\varepsilon_{\mathrm{p}}\right)$ strains are higher the higher the strain rate and the lower the temperature, showing high level of work hardening as well as the DRV mechanism acting. This contributed to retard the DRX associated to the moderate $\operatorname{SFE}\left(\gamma_{\text {efe }} \sim 21 \mathrm{~mJ} / \mathrm{m}^{2}\right)$. This SFE applicable for the material studied here was calculated by using the empirical procedure described in reference 4 .

(ii) The constitutive equation that best represented the thermomechanical behavior of the deformation mechanisms of AISI 410 steel, with respect to critical, peak and steadystate strains and stresses, according to the Zener-Hollomon parameter, was:

$Z=\dot{\varepsilon} \exp \left(\frac{204.954}{R T}\right)=5.54 \times 10^{7}\left[\sinh \left(0.00952 \sigma_{p}\right)\right]^{3.18}$

(iii)After the reaching the peak strain, the material's softening mechanism was found to be governed predominantly by the parameters $t_{0.5}$ and $\mathrm{n}$, which represent the form and kinetics of DRX in the steady state. This was obtained after large strains with low Avrami exponent (n) and high $t_{0.5}$, with dynamically recrystallized grains and the presence of precipitates of chromium carbide $\left(\mathrm{Cr}_{23} \mathrm{C}_{6}\right)$ and $\delta$ ferrite at the boundaries of martensitic grains.

\section{Acknowledgements}

The authors thank the Brazilian research funding agencies FAPEMA(Maranhão Foundation for Scientific Research and Development), the Federal Institute of Maranhão (IFMA) and $\mathrm{CNPq}$ (National Council for Scientific and Technological Development). They would also like to acknowledge Prof. In-Ho Jung from McGill University for providing access to FactSage thermodynamic software.

\section{References}

1. Ebrahimi GR, Keshmiri H, Maldar AR, Momeni A. Dynamic Recrystallization Behavior of $13 \% \mathrm{Cr}$ Martensitic Stainless Steel under Hot Working Condition. Journal of Materials Science \& Technology. 2012;28(5):467-473.

2. Montheillet F, Jonas JJ. Dynamic recrystallization. In: Trigg GL, ed. Encyclopedia of Applied Physics, volume 16. Hoboken: Wiley-VHC; 1996. p. 205-225.

3. Baczynski J, Jonas JJ. Torsion textures produced by dynamic recrystallization in $\alpha$-iron and two interstitial-free steels. Metallurgical and Materials Transactions A. 1998;29(2):447-462.

4. Dai QX, Wang AD, Cheng XN, Luo XM. Stacking fault energy of cryogenic austenitic steels. Chinese Physics. 2002;11(6):596.

5. Ebrahimi GR, Keshmiri H, Mazinani M, Maldar A, Haghshenas M. Multi-stage thermomechanical behavior of AISI 410 martensitic steel. Materials Science and Engineering: A. 2013;559:520-527.

6. Nkhoma RKC, Siyasiya CW, Stumpf WE. Hot workability of AISI 321 and AISI 304 austenitic stainless steels. Journal of Alloys and Compounds. 2014;595:103-112.
7. Najafizadeh A, Jonas JJ. Predicting the Critical Stress for Initiation of Dynamic Recrystallization. ISIJ International. 2006;46(11):1679-1684.

8. Momeni A, Dehghani K, Ebrahimi GR. Modeling the initiation of dynamic recrystallization using a dynamic recovery model. Journal of Alloys and Compounds. 2011;509(39):9387-9393.

9. Mirzadeh H, Najafizadeh A. Flow stress prediction at hot working conditions. Materials Science and Engineering: A. 2010;527(4-5):1160-1164.

10. Jafari M, Najafizadeh A. Comparison between the Methods of Determining the Critical Stress for Initiation of Dynamic Recrystallization in 316 Stainless Steel. Journal of Materials Science \& Technology. 2008;24(6):840-844.

11. Poliak EI, Jonas JJ. A one-parameter approach to determining the critical conditions for the initiation of dymanic recrystallization. Acta Materialia. 1996;44(1):127-136.

12. Poliak EI, Jonas JJ. Initiation of Dynamic Recrystallization in Constant Strain Rate Hot Deformation. ISIJ International. 2003;43(5):684-691.

13. Jonas JJ, Quelennec X, Jiang L, Martin E. The Avrami kinetics of dynamic recrystallization. Acta Materialia. 2009;57(9):2748-2756.

14. Isfahany AN, Saghafian H, Borhani G. The effect of heat treatment on mechanical properties and corrosion behavior of AISI420 martensitic stainless steel. Journal of Alloys and Compounds. 2011;509(9):3931-3936.

15. Bissey-Breton S, Vignal V, Herbst F, Coudert JB. Influence of Machining on the Microstructure, Mechanical Properties and Corrosion Behaviour of a Low Carbon Martensitic Stainless Steel. Procedia CIRP. 2016;46:331-335.

16. Fields DS, Backofen WA. Determination of Strain-Hardening Characteristics By Torsion Testing. ASTM Proceeding. 1957;57:1259-1272.

17. Jonas JJ, Poliak EI. The Critical Strain for Dynamic Recrystallization in Rolling Mills. Materials Science Forum. 2003;426-432:57-66.

18. Sellars CM, Tegart WJM. La relation entre la résistance et la structure dans la deformation à chaud. Memoires Scientifiques de la Revue de Metallurgie. 1966;63:731-746.

19. Uvira JL, Jonas JJ. Hot compression of Armco iron and silicon steel. Transactions of the Metallurgical Society of AIME. 1968;242:1619-1626.

20. Rodrigues SF, Silva ES, Reis GS, Sousa RC, Balancin O. Prediction of hot flow plastic curves of ISO 5832-9 steel used as orthopedic implants. Materials Research. 2014;17(2):436-444.

21. Sousa RC, Silva ES, Jorge AM Jr., Cabrera JM, Balancin O. Dynamic recovery and dynamic recrystallization competition on a Nb- and $\mathrm{N}$ - bearing austenitic stainless steel biomaterial: Influence of strain rate and temperature. Materials Science and Engineering: A. 2013;582:96-107.

22. Silva ES, Sousa RC, Jorge AM Jr., Balancin O. Hot deformation behavior of an $\mathrm{Nb}$ - and $\mathrm{N}$ - bearing austenitic stainless steel biomaterial. Materials Science and Engineering: A. 2012;543:69-75. 
23. Cardoso PHS, Kwietniewski C, Porto JP, Reguly A, Strohaecker TR. The influence of delta ferrite in the AISI 416 stainless steel hot workability. Materials Science and Engineering: $A$. 2003;351(1-2):1-8.

24. Chakraborty G, Das CR, Albert SK, Bhaduri AK, Paul VT, Panneerselvam G, et al. Study on tempering behaviour of AISI 410 stainless steel. Materials Characterization. 2015;100:81-87.
25. Kenvalo E, Ebrahimi GR, Sani SAA, Momeni A. Dynamic recrystallization kinetics of AISI 403 stainless steel using hot compression test. Iranian Journal of Materials Forming. 2014;1(2):32-43.

26. Lei X, Feng Y, Zhang J, Fu A, Yin C, Macdonald DD. Impact of Reversed Austenite on the Pitting Corrosion Behavior of Super 13Cr Martensitic Stainless Steel. Electrochimica Acta. 2016;191:640-650. 